\title{
Cerebral Sarcoidosis
}

National Cancer Institute

\section{Source}

National Cancer Institute. Cerebral Sarcoidosis. NCI Thesaurus. Code C35441.

Sarcoidosis of the cerebrum. 